Caracterização e Avaliação das Propriedades Adsortivas da Casca de Laranja na Remoção do Corante Direct Blue 86

\author{
Formica, B. C.; Brudzinski, P. B.; Carvalho, K. Q. de*; Floriano, J. B.; \\ Passig, F. H.; Liz, M. V.
}

Rev. Virtual Quim., 2017, 9 (2), 608-625. Data de publicação na Web: 4 de abril de 2017

http://rvq.sbq.org.br

\title{
Characterization and Evaluation of the Orange Peel Adsorptive Properties in the Dye Direct Blue 86 Removal
}

\begin{abstract}
The use of powdered from orange peel (Citrus sinensis) as low cost adsorbent for the removal of the dye Direct Blue 86 , routinely used in the textile industry, was the objective of this work. A porous structure compatible with the adsorption of molecules with dimensions of up to 15 micrometers was verified in the characterization of the orange peel powder (OPP). The OPP answered the ABNT NBR 2133 norm showing lower humidity content of $8 \%$. The ash content indicated few impurities in the material, with a value of $(2.79 \pm 0.06) \%$. The methodology used in adsorption experiments did not allow quantification of the dye in the solutions, leading to an investigation of the possible causes. The results showed the D-limonene, orange peel component, as responsible for the non-viability of the methodology employed, so it was not possible to quantify the study through the contact time of variation (adsorption kinetics), $\mathrm{pH}$, temperature and adsorption isotherm by this method.
\end{abstract}

Keywords: Adsorption; Agro-industrial waste; Spectroscopy; Textile Industry; Color removal.

Resumo

O uso de pó de casca de laranja (Citrus sinensis) como adsorvente de baixo custo na remoção do corante Direct Blue 86, usado rotineiramente na indústria têxtil, foi o objetivo deste trabalho. Um estrutura porosa compatível com a adsorção de moléculas com dimensões de até $15 \mu \mathrm{m}$ foi verificada na caracterização do pó da casca da laranja ( $\mathrm{PCL}$ ). O PCL atendeu a norma $A B N T$ NBR 2133 apresentando teor de umidade abaixo de $8 \%$. O teor de cinzas indicou poucas impurezas no material, com valor de $(2,79 \pm 0,06) \%$. A metodologia empregada nos ensaios de adsorção não permitiu a quantificação do corante nas soluções, levando a uma investigação das possíveis causas. Os resultados apresentaram o D-Limoneno, componente da casca da laranja, como responsável pela inviabilização da metodologia empregada, portanto, não foi possível quantificar o estudo através da variação de tempo de contato (cinética de adsorção), pH, temperatura e isoterma de adsorção através deste método.

Palavras-chave: Adsorção; Resíduo agroindustrial; Espectroscopia; Indústria Têxtil; Remoção de cor.

* Universidade Tecnológica Federal do Paraná, Departamento Acadêmico de Construção Civil, Câmpus Curitiba, Sede Ecoville, CEP 81280-340, Curitiba-PR, Brasil.

Mkaquerne@utfpr.edu.br DOI: $10.21577 / 1984-6835.20170036$ 


\title{
Caracterização e Avaliação das Propriedades Adsortivas da Casca de Laranja na Remoção do Corante Direct Blue 86
}

\author{
Barbara C. Formica, ${ }^{a}$ Patricia B. Brudzinski, ${ }^{a}$ Karina Q. de Carvalho, ${ }^{b}$ João \\ B. Floriano, ${ }^{a}$ Fernando H. Passig, ${ }^{a}$ Marcus Vinicius de Liz ${ }^{\mathrm{a}}$ \\ ${ }^{a}$ Universidade Tecnológica Federal do Paraná, Departamento Acadêmico de Química e \\ Biologia, Câmpus Curitiba, Sede Ecoville, CEP 81280-340, Curitiba-PR, Brasil.

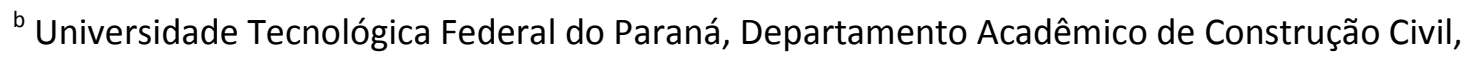 \\ Câmpus Curitiba, Sede Ecoville, CEP 81280-340, Curitiba-PR, Brasil.
}

*kaquerne@utfpr.edu.br

\section{Introdução}

\section{Materiais e Métodos}

2.1. Coleta e preparo do material adsorvente

2.2. Teor de umidade

2.3. Teor de cinzas

2.4. Análise granulométrica

2.5. Espectroscopia no infravermelho

2.6. Microscopia Eletrônica de Varredura (MEV)

2.7. Índice de iodo

2.8. Índice de azul de metileno

\section{Resultados e Discussão \\ 4. Conclusões}

\section{Introdução}

Os corantes atualmente empregados pela indústria têxtil são compostos orgânicos sintéticos complexos, muitos do quais tóxicos e não biodegradáveis, o que exige aplicação de técnicas eficientes para seu tratamento.

A baixa (ou quase nula) biodegradabilidade de alguns corantes impede o uso de técnicas convencionais de tratamento biológico, sendo dada preferência para métodos físicos e/ou químicos, ${ }^{1}$ dentre os quais se destaca a adsorção, por ser processo eficiente e econômico. ${ }^{2}$ Neste processo tem sido empregados os mais variados materiais adsorventes, assim classificados por serem porosos e com elevada área superficial para uma dada massa. ${ }^{3}$

Os adsorventes mais utilizados comercialmente são carvão ativado, zeólita, sílica gel e alumina ativada, porém devido aos 
custos tem sido estudados adsorventes alternativos no tratamento de efluentes industriais com destaque para os resíduos agrícolas. $^{4}$

Dentre estes, merecem destaque os resíduos gerados nas indústrias de laranja, cuja acumulação acarreta na ocupação de terrenos e consequentemente na poluição por compostos fenólicos devido ao seu descarte inadequado. Uma vez que a casca de laranja está disponível nas indústrias de processamento, a reciclagem destes resíduos para tratamento de águas residuárias não apresenta somente vantagem econômica, mas, também contribui para minimização de problemas de disposição deste resíduo. ${ }^{5}$

A casca da laranja é em grande parte composta de pectina de celulose, hemicelulose, lignina e outros compostos de baixa massa molecular, incluindo calcário. Ela pode ser utilizada como bioadsorvente eficiente e de baixo custo para remoção de corantes orgânicos e metais poluentes do efluente industrial. Além disso, a casca de laranja é uma alternativa de adsorvente por sua abundância na natureza e por ser biodegradável. $^{6}$

Neste contexto o objetivo deste trabalho foi avaliar o pó da casca da laranja como adsorvente na remoção do corante têxtil Direct Blue 86.

\section{Materiais e Métodos}

\subsection{Coleta e preparo do material adsorvente}

As cascas de laranja, obtidas em restaurantes da região de Curitiba, foram colocadas em bandejas metálicas e levadas à estufa para secagem a $45{ }^{\circ} \mathrm{C}$ por $36 \mathrm{~h}$. Após esta etapa, as cascas foram trituradas em liquidificador industrial até obtenção de um pó fino. Posteriormente, este pó foi acondicionado em recipientes plásticos mantidos em freezer a temperatura aproximada de $-4{ }^{\circ} \mathrm{C}$. Antes de cada ensaio, o pó foi mantido em dessecador durante $24 \mathrm{~h}$ para remoção da umidade residual.

\subsection{Teor de umidade}

A determinação do teor de umidade foi realizada conforme a norma ASTM D2867, $2004^{7}$ em triplicata. Massas de 2,0 g do PCL foram colocadas em três béqueres de $50 \mathrm{~mL}$ (cada) e determinadas as massas dos conjuntos. Em seguida, os béqueres foram mantidos em estufa (MedClave, mod. 2) a $150{ }^{\circ} \mathrm{C}$ por 3 h. Após resfriamento em dessecador, foram realizadas novas determinações das massas dos conjuntos.

\subsection{Teor de cinzas}

A determinação do teor de cinzas foi realizada segundo metodologia descrita na norma ASTM D2866-94, 1994 ${ }^{8}$ em triplicata. Cápsulas de porcelana foram calcinadas em mufla (Zezimaq, mod. FHMP DigiMec) a $650{ }^{\circ} \mathrm{C}$ por uma hora. Após o resfriamento, foram determinadas as massas das cápsulas em balança analítica (Precisa, mod. Mark 210A). Massas de aproximadamente $9 \mathrm{~g}$ do $\mathrm{PCL}$ foram secas em estufa (MedClave, mod. 2) a $150^{\circ} \mathrm{C}$ por $3 \mathrm{~h}$ e em seguida transferidas para o dessecador. Aproximadamente $5 \mathrm{~g}$ do $\mathrm{PCL}$ seco foram colocados nas cápsulas e calcinadas a $650{ }^{\circ} \mathrm{C}$ por $6 \mathrm{~h}$. Após este tempo, as cápsulas foram resfriadas em dessecador e determinadas suas massas na balança analítica.

\subsection{Análise granulométrica}

A composição granulométrica foi determinada segundo procedimentos descritos na norma ABNT NBR NM 248, 2001. ${ }^{9}$ Massa de $300 \mathrm{~g}$ do PCL foi previamente seca em estufa (MedClave, mod. 2) a $110^{\circ} \mathrm{C}$ e resfriada à temperatura ambiente em dessecador. Foi montado um conjunto de 5 peneiras com abertura de 
malha em ordem crescente da base para o topo, de $(0,075 \pm 0,010 ; 0,149 \pm 0,001 ; 0,300$ $\pm 0,001 ; 0,600 \pm 0,001 ; 1,180 \pm 0,010) \mathrm{mm}$. A amostra foi colocada sobre o conjunto e submetida à agitação durante $8 \mathrm{~min}$ em agitador mecânico. Cada peneira foi retirada do conjunto, e o material nela contido foi transferido para um cadinho (previamente tarado), para determinação da massa da fração retida naquela peneira.

\subsection{Espectroscopia no infravermelho}

O PCL foi previamente seco em estufa a $45^{\circ} \mathrm{C}$ por $36 \mathrm{~h}$ (estufa MedClave, mod. 2). A análise de infravermelho foi realizada em um espectrômetro Shimadzu - FTIR, modelo 8300, com acessório de ATR com cristal de seleneto de zinco. Após a obtenção do espectro de fundo (background), uma pequena massa da amostra foi colocada sobre o acessório de ATR, e os espectros foram obtidos na faixa de 4000 a $650 \mathrm{~cm}^{-1}$, usando 32 varreduras acumuladas para formar o espectro final.

\subsection{Microscopia Eletrônica de Varredura (MEV)}

A amostra seca e particulada foi fixada a um suporte metálico (stub) com fita duplaface para posteriormente ser metalizada e proceder à varredura. As imagens foram obtidas no microscópio de varredura eletrônica Zeiss, modelo EVO MA15, com tensão de $20,00 \mathrm{kV}$ e diâmetro do feixe $10,0 \mathrm{~mm}$.

\section{7. Índice de iodo}

O índice de iodo foi determinado de acordo com procedimentos descritos nas normas NBR 12073, $1991 a^{10}$ e ASTM D4607, $2014^{11}$ e a apresentação dos resultados foi feita de acordo com a ASTM D4607, 2014 ${ }^{11}$, em triplicata. Primeiramente, foram preparadas soluções de dicromato de potássio $0,01 \mathrm{~mol} \cdot \mathrm{L}^{-1}$, solução de ácido clorídrico $(\mathrm{HCl})$ 1:5 $(\mathrm{v} / \mathrm{v})$, solução indicadora de amido $0,5 \%(\mathrm{~m} / \mathrm{v})$, solução de tiossulfato de sódio $0,1 \mathrm{~mol} \cdot \mathrm{L}^{-1}$ e solução de iodo $0,05 \mathrm{~mol} \cdot \mathrm{L}^{-1}$, de acordo com metodologia descrita no Anexo B da NBR 12073 (1991a). ${ }^{10}$

Massas de $(2,0000 \pm 0,0001),(3,0000 \pm$ $0,0001)$ e $(4,0000 \pm 0,0001) \mathrm{g}$ do $\mathrm{PCL}$ (determinadas na balança analítica Precisa, mod. Mark 210A), previamente seco em estufa (MedClave, mod. 2) a $130{ }^{\circ} \mathrm{C}$ durante $3 \mathrm{~h}$, foram transferidas para béqueres de $250 \mathrm{~mL}$ e acrescidas de $10 \mathrm{~mL}$ da solução de $\mathrm{HCl}$. Os béqueres foram aquecidos até a ebulição da solução, e então resfriados a temperatura ambiente. Em seguida, foram adicionados $100 \mathrm{~mL}$ da solução de iodo em cada béquer, que foram agitados durante $30 \mathrm{~s}$.

Os conteúdos dos béqueres foram filtrados e titulados conforme procedimento na ASTM D4607, 2014 ${ }^{11}$.

Os cálculos dos fatores de correção das soluções e do índice de iodo encontram-se descritos na norma NBR 12073 (1991a). ${ }^{10}$

\section{8. Índice de azul de metileno}

O índice de Azul de Metileno foi determinado de acordo com metodologia descrita por Xavier, 2007, baseada na norma JIS 1474/1991, em triplicata. ${ }^{12}$

Foram preparadas três soluções, sendo ácido etanóico $5 \%(\mathrm{v} / \mathrm{v})$, ácido etanóico $0,25 \%$ (v/v) e azul de metileno (solução estoque). Para a solução de azul de metileno, avalia-se inicialmente a umidade da substância por secagem de uma amostra de $1,2 \mathrm{~g}$ até massa constante; após, pesa-se $0,1200 \mathrm{~g}$ de azul de metileno, descontado o teor de umidade, e faz-se a dissolução em volume de ácido etanóico $5 \%(\mathrm{v} / \mathrm{v})$ suficiente para aferir um balão volumétrico de 1,00 L.

Em seguida, preparou-se uma curva de 
calibração com soluções de $\mathrm{AM}$ nas concentrações de $1,2 \times 10^{-3}, 2,4 \times 10^{-3}, 3,6 \times 10^{-3}$, $4,8 \times 10^{-3}, 6,0 \times 10^{-3}$ e $7,2 \times 10^{-3} \mathrm{~g} \cdot \mathrm{L}^{-1}$, obtidas a partir da solução estoque de AM por diluição com a solução de ácido etanóico $0,25 \%(\mathrm{v} / \mathrm{v})$. Cada diluição foi analisada no UV-visível com espectrofotômetro Hach (mod. DR 5000), de modo a registrar os respectivos valores de absorbância. Por regressão linear, obteve-se a equação da reta que relaciona absorbância e concentração residual de AM.

Cada amostra do PCL foi seca em estufa (MedClave, mod. 2) por $2 \mathrm{~h}$ a $150(5){ }^{\circ} \mathrm{C}$ e resfriada em dessecador até atingir a temperatura ambiente. Três erlenmeyers de $250 \mathrm{~mL}$ receberam $0,0200 \mathrm{~g}$ de amostra e $50 \mathrm{~mL}$ da solução estoque de AM (cada), e foram mantidos sob agitação a $143 \mathrm{rpm}$, a temperatura de $26^{\circ} \mathrm{C}$, por 30 minutos. Após este tempo, cada solução foi filtrada em papel filtro, desprezando os primeiros $20 \mathrm{~mL}$. Uma alíquota de $1,00 \mathrm{~mL}$ da solução restante foi transferida para um balão volumétrico de $100 \mathrm{~mL}$, que foi aferido com solução de ácido etanóico $0,25 \%(\mathrm{v} / \mathrm{v})$.

Por fim, cada amostra foi analisada no espectrofotômetro UV-visível, na faixa de 400 a $800 \mathrm{~nm}$. Com base na curva de calibração, foi possível obter as concentrações de AM das amostras a partir dos valores da absorbância medidos no comprimento de onda $665 \mathrm{~nm}$. Para o branco foi utilizada solução de ácido etanóico 0,25\% (v/v).

\section{Ponto de Carga Zero $\left(\mathrm{pH}_{\mathrm{PCZ}}\right)$}

0 ponto de carga zero $\left(\mathrm{pH}_{\mathrm{PCZ}}\right)$ foi determinado através de adaptação da metodologia descrita por Couto Junior, 2012, em duplicata. ${ }^{13}$ Onze erlenmeyers de $125 \mathrm{~mL}$ foram preenchidos com $100 \mathrm{~mL}$ de água destilada. Em cada um destes, o pH foi ajustado para os valores unitários de 2 a 12 . Após, $0,10 \mathrm{~g}$ de PCL foram acrescentados a cada erlenmeyer, e estes foram mantidos em mesa agitadora, a $120 \mathrm{rpm}$ e à temperatura de $25{ }^{\circ} \mathrm{C}$ durante uma hora. O conteúdo de cada erlenmeyer foi filtrado em papel filtro qualitativo e feita a medição do pH.

\section{Curva de calibração para análise quantitativa do corante Direct Blue 86}

Foi preparada uma solução estoque do corante $D B \quad 86$ (Corasol Turquesa/Azul Turquesa GLL 160\%) com água destilada com concentração de $1,5 \times 10^{-1} \mathrm{~g} \cdot \mathrm{L}^{-1}$. O corante foi cedido pela Siebert Química Ltda, Coratex, Gaspar, SC. Com um pHmetro de bancada PHTEK, previamente calibrado, foi medido o $\mathrm{pH}$ da solução.

A partir da solução estoque, diferentes soluções de concentrações $3,8 \times 10^{-3} ; 7,5 \times 10^{-3}$; $1,5 \times 10^{-2} ; 2,3 \times 10^{-2} ; 3,0 \times 10^{-2} ; 3,8 \times 10^{-2}$ e $4,5 \times 10^{-2}$ $\mathrm{g} \cdot \mathrm{L}^{-1}$ foram preparadas $\mathrm{e}$ obtidos os respectivos espectros de UV-visível. Para tal medida foi empregado um espectrofotômetro Hach UV-Vis, modelo DR 5000.

A partir das diferentes soluções preparadas, os espectros foram obtidos, e construiu-se um gráfico da absorbância no comprimento de onda $620 \mathrm{~nm}$ (comprimento de onda de absorbância máximo) versus concentração, obtendo-se a curva de calibração com equação da regressão linear Abs $=\left(-9,6317 \times 10^{-4} \pm 0,0102\right)+(36,2092 \pm$ $0,3779) \cdot\left[C /\left(g \cdot L^{-1}\right)\right]$, em que Abs corresponde à absorbância e $C$ à concentração de $D B 86\left(\mathrm{R}^{2}\right.$ $=0,99935)$.

A sensibilidade do método resultou em 36,2092 , o limite de deteç̧ão em 9,3233×10 ${ }^{4} \mathrm{~g} \cdot \mathrm{L}^{-1}$ e o limite de quantificação em $2,8252 \times 10^{-3} \mathrm{~g} \cdot \mathrm{L}^{-1} .^{14}$

\section{Análise quantitativa de corante adsorvido sobre pó de casca de laranja}

Para o ensaio de adsorção, foram adicionados $100 \mathrm{~mL}$ da solução estoque em erlenmeyers de $125 \mathrm{~mL}$ contendo massas de $1,0 \mathrm{~g}$ do PCL. Os erlenmeyers foram colocados em mesa agitadora Shaker, modelo SL222, e mantidos sob agitação 
constante de $120 \mathrm{rpm}$ a temperatura de 30 ${ }^{\circ} \mathrm{C}$. Alíquotas de $10 \mathrm{~mL}$ foram retiradas dos erlenmeyers em intervalos de tempo de aproximadamente $12 \mathrm{~h}$, durante $6 \mathrm{~d}$ e $12 \mathrm{~h}$.

O adsorvente foi separado da solução por filtração em papel filtro qualitativo com diâmetro de $18,5 \mathrm{~cm}$. A concentração residual do adsorvato foi determinada através das medidas de absorbância e da curva de calibração, sendo construído o gráfico concentração versus tempo. Também foram obtidos espectros de UV-visível para cada retirada de alíquota.

\section{Influência do pH na análise quantitativa do ensaio de adsorção}

Para avaliar a influência do $\mathrm{pH}$ na análise quantitativa no ensaio de adsorção, foi preparada nova solução a partir da solução estoque de $1,5 \times 10^{-1} \mathrm{~g} \cdot \mathrm{L}^{-1}$ do corante. A solução de concentração $1,5 \times 10^{-2} \mathrm{~g} \cdot \mathrm{L}^{-1}$ teve pH ajustado para 2,06; 4,40; 6,00; 8,89; 10,$51 ; 12,48$ com adição de solução de $5,0 \times 10^{-3} \mathrm{~mol} \cdot \mathrm{L}^{-1}$ de ácido sulfúrico e de solução de $5,0 \times 10^{-3} \mathrm{~mol} \cdot \mathrm{L}^{-1}$ de hidróxido de sódio em pHmetro de bancada PHTEK, previamente calibrado. Foram obtidos espectros de UV-visível para cada ajuste de $\mathrm{pH}$.

Influência dos componentes da casca de laranja na análise quantitativa do ensaio de adsorção

A verificação da interferência dos componentes da casca na adsorção foi feita em um segundo ensaio, no qual foram adicionados $100 \mathrm{~mL}$ de água destilada em erlenmeyers de $125 \mathrm{~mL}$, contendo massas de $1,0 \mathrm{~g}$ do PCL. Os erlenmeyers foram mantidos na mesa agitadora Shaker, modelo SL222, sob agitação constante de $120 \mathrm{rpm}$ a temperatura de $30{ }^{\circ} \mathrm{C}$. Alíquotas de $10 \mathrm{~mL}$ foram retiradas dos erlenmeyers que continham $\mathrm{PCL}$ e água destilada em intervalos de tempo de aproximadamente 12 h, durante $4 \mathrm{~d}$ para obtenção de espectros de UV-visível para cada retirada de alíquota.

\section{Resultados e Discussão}

\section{Teor de umidade}

O teor de umidade obtido para a amostra de PCL foi de $(6,86 \pm 0,21) \%$. Khalfaoui et al., 2014 registraram teor de 5,25\%, para cascas de laranjas calcinadas, ${ }^{15}$ enquanto Miranda et al., 2009 e Kamsonlian et al., 2011 encontraram $9,2 \%$ e $10,32 \%,{ }^{16,17}$ respectivamente, para cascas de laranja secas em estufa. Na norma ABNT NBR 2133, 1991b é determinado que carvões ativados não devem apresentar teor de umidade superior a $8 \%$, logo, o PCL atende a esta especificação. $^{18}$

\section{Teor de cinzas}

O teor de cinzas encontrado para o $\mathrm{PCL}$ foi $(2,79 \pm 0,06) \%$, e é próximo aos valores indicados por Nassar et al., 2008, de 2,61\%, ${ }^{19}$ Miranda et al., 2009, de 2,94\%, ${ }^{16}$ e Kamsonlian et al., 2011, de 3,10\%, ${ }^{17}$ para cascas de laranja secas em estufa. Um valor próximo, 2,986 \%, também foi observado por Khalfaoui et al., 2014 para o teor de cinzas de cascas de laranja calcinadas. ${ }^{15}$

\section{Análise granulométrica}

Através do ensaio granulométrico, foi possível classificar o PCL de acordo com a massa retida, porcentagem retida e porcentagem retida acumulada em cada peneira (Tabela 1).

A distribuição das partículas de $\mathrm{PCL}$ concentra-se na faixa de $(0,300 \pm 0,001) \mathrm{mm}$, sendo que a maior porcentagem das 
partículas da amostra, $64,34 \%$, foi retida nesta peneira.

\section{Estrutura molecular}

As bandas mais intensas correspondem ao grupo funcional álcool (deformação axial de
O-H, em ligação de hidrogênio intermolecular, $3293 \mathrm{~cm}^{-1}$ ), metileno (deformação axial de $\mathrm{C}-\mathrm{H}, 2917 \mathrm{~cm}^{-1}$ ) e aldeído (deformação $\mathrm{C}=0,1735 \mathrm{~cm}^{-1}$ e 1606 $\mathrm{cm}^{-1}$ ). As bandas na região de 1400 a 1220 $\mathrm{cm}^{-1}$ representam a deformação angular de $\mathrm{C}-\mathrm{H}$ e o pico em $1014 \mathrm{~cm}^{-1}$ é relativo à deformação vibracional C-O (Figura 1).

Tabela 1. Composição granulométrica do PCL

\begin{tabular}{c|c|c|c}
\hline Abertura da peneira / $\mathbf{~ m m}$ & Massa retida / $\mathbf{g}$ & Porcentagem retida / \% & $\begin{array}{c}\text { Porcentagem } \\
\text { retida acumulada / \% }\end{array}$ \\
\hline $1,180 \pm 0,010$ & $0,0687 \pm 0,0001$ & 0,02 & 0,02 \\
\hline $0,600 \pm 0,001$ & $14,1230 \pm 0,0001$ & 4,73 & 4,76 \\
\hline $0,300 \pm 0,001$ & $191,9200 \pm 0,0001$ & 64,34 & 69,09 \\
\hline $0,149 \pm 0,001$ & $82,8500 \pm 0,0001$ & 27,77 & 96,87 \\
\hline $0,075 \pm 0,001$ & $9,2651 \pm 0,0001$ & 3,11 & 99,97 \\
\hline Fundo & $0,0860 \pm 0,0001$ & 0,03 & 100,00 \\
\hline Total & $\mathbf{2 9 8 , 3 1} \pm \mathbf{0 , 0 1}$ & $\mathbf{1 0 0 , 0 0}$ & \\
\hline
\end{tabular}

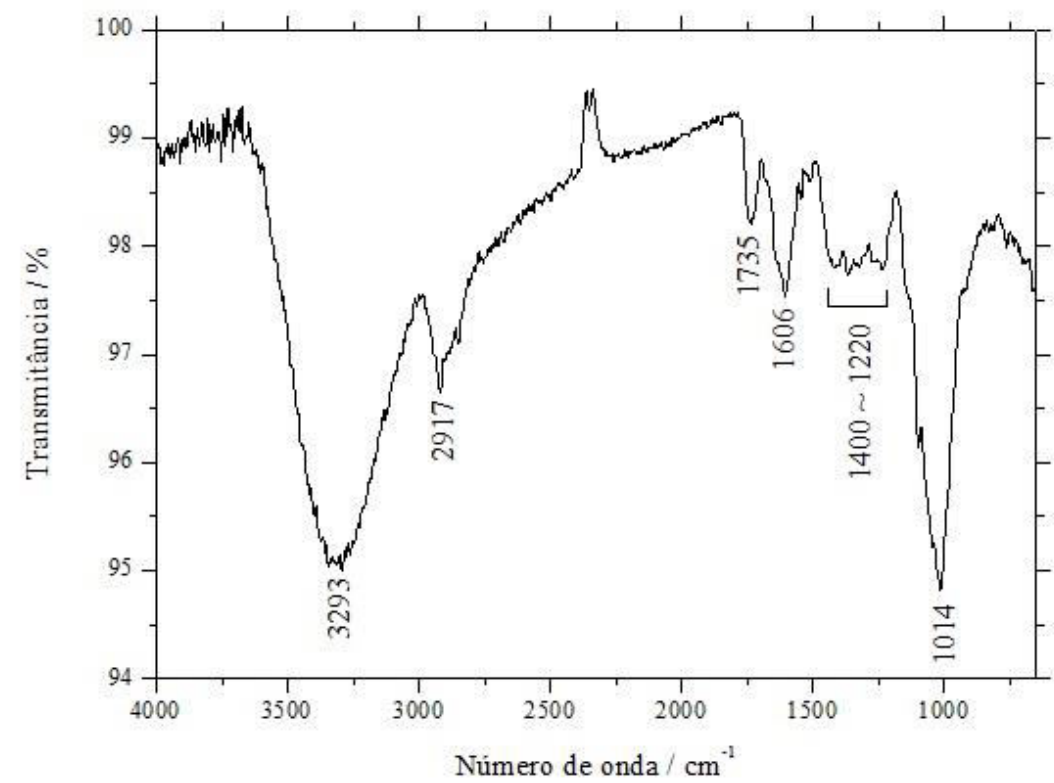

Figura 1. Espectro de infravermelho do PCL

Mafra et al., 2013 obtiveram espectro de infravermelho similar ao observado neste trabalho para $\mathrm{O} \mathrm{PCL}$, mas com menor intensidade da banda na região de $1000 \mathrm{~cm}$ ${ }^{1.20}$ Miranda et al., 2009 notaram banda forte em $3348 \mathrm{~cm}^{-1}$ indicativa de grupos álcool e fenol, bandas em 2920 e $2963 \mathrm{~cm}^{-1}$ representando alcanos; bandas entre 1699 e $1704 \mathrm{~cm}^{-1}$, denotando a presença de ácidos 


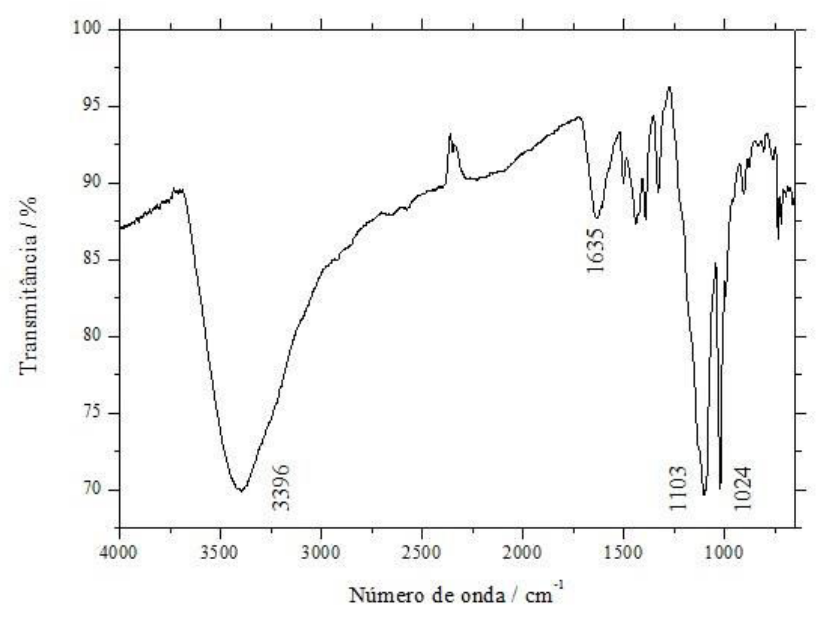

(a)

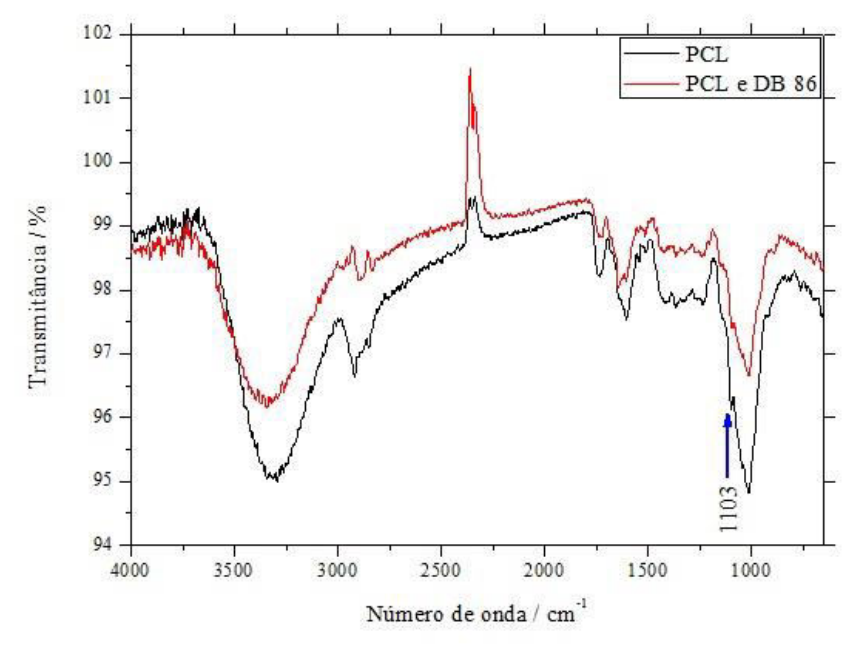

(b)

Figura 2. Espectro de infravermelho antes (a) e após a adsorção (b) do corante $D B 86$

É possível observar banda forte em $3396 \mathrm{~cm}^{-1}$, típica de aminas secundárias, banda em $1635 \mathrm{~cm}^{-1}$ que representa a ligação $\mathrm{N}-\mathrm{H}$, duas bandas fortes e estreitas em 1103 $\mathrm{cm}^{-1}$ e $1024 \mathrm{~cm}^{-1}$, que indicam o estiramento da ligação $\mathrm{S}=0$.

O PCL possui as mesmas bandas espectrais antes e após a adsorção do corante $D B$ 86. As bandas características do $D B 86$ se sobrepõem às bandas principais dos espectros do PCL, antes e após a adsorção, com exceção à banda em $1103 \mathrm{~cm}^{-1}$, que passa a não ser mais observada. Dado que o espectro de infravermelho fornece intensidades relativas, conclui-se que o $D B 86$ está presente em quantidade inferior à do $\mathrm{PCL}$, não sendo detectável por esta técnica. 


\section{Análise superficial}

$\mathrm{Na}$ Figura 3 são apresentadas as fotomicrografias do PCL antes e após a adsorção do corante $D B 86$ obtidas por MEV.

Os poros do PCL apresentam estrutura heterogênea, como observado por Arami et al., 2005 e Mafra et al., 2013, ${ }^{21,20}$ e maior quantidade de poros com dimensões de 10,0 a $15,0 \mu \mathrm{m}$, que podem ser classificados como macroporos de acordo com a IUPAC, $1997 .{ }^{22}$ As irregularidades na estrutura física do material podem ser consequência da secagem em estufa, que leva à degradação do material pectínico, como também foi observado por Xiao e Gao, 2012 em gel de Aloe vera submetido a tratamento térmico. ${ }^{23}$

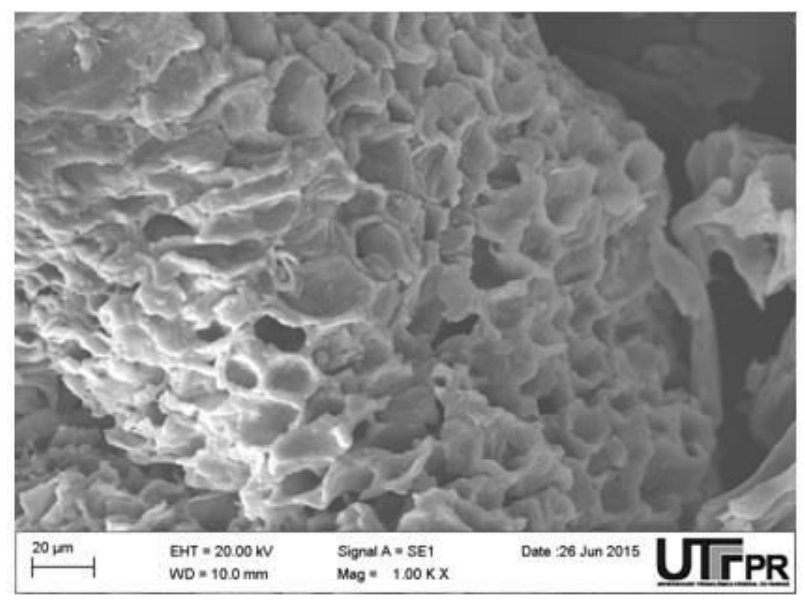

a)

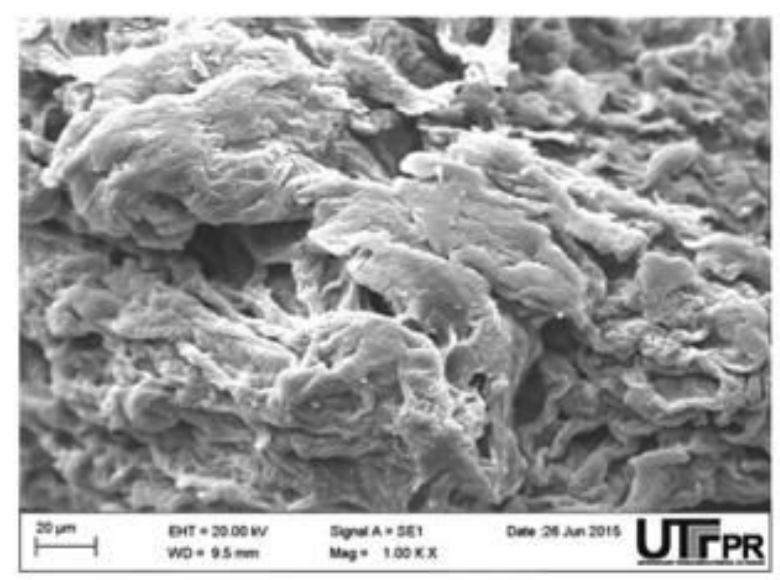

b)

Figura 3. Fotomicrografias do $P C L$ antes (a) e após (b) a adsorção do $D B 86$

Após os ensaios de adsorção, o PCL foi separado da solução de corante através de filtração em papel-filtro. O filtrado foi acondicionado em dessecador para remoção da umidade e, após, procedeu-se à visualização no MEV. Notam-se alterações morfológicas na estrutura do $\mathrm{PCL}$, sugerindo a saturação dos poros pelo corante; o mesmo efeito foi observado por Arami et al., 2005 na adsorção de corantes diretos em PCL. ${ }^{21}$ 


\section{Índice de iodo}

Com base nos valores calculados para quantidade de iodo adsorvida por grama de amostra $(X / M)$ e concentração residual de iodo $\left(C_{R}\right)$, foi traçado o gráfico $X / M$ versus $C_{R}$, em escala logarítmica, para cada uma das amostras, com ajuste linear para os três pontos (Figura 4).

Pelo ajuste linear dos pontos, obteve-se a equação da reta $\left(R^{2}=0,99382\right)$ :

$$
\left[(\mathrm{X} / \mathrm{M}) /\left(\mathrm{mg} \cdot \mathrm{g}^{-1}\right)\right]=19832,90 \cdot\left[\mathrm{C}_{\mathrm{R}} /\left(\mathrm{mol} \cdot \mathrm{L}^{-1}\right)\right]
$$
$+58,9974$

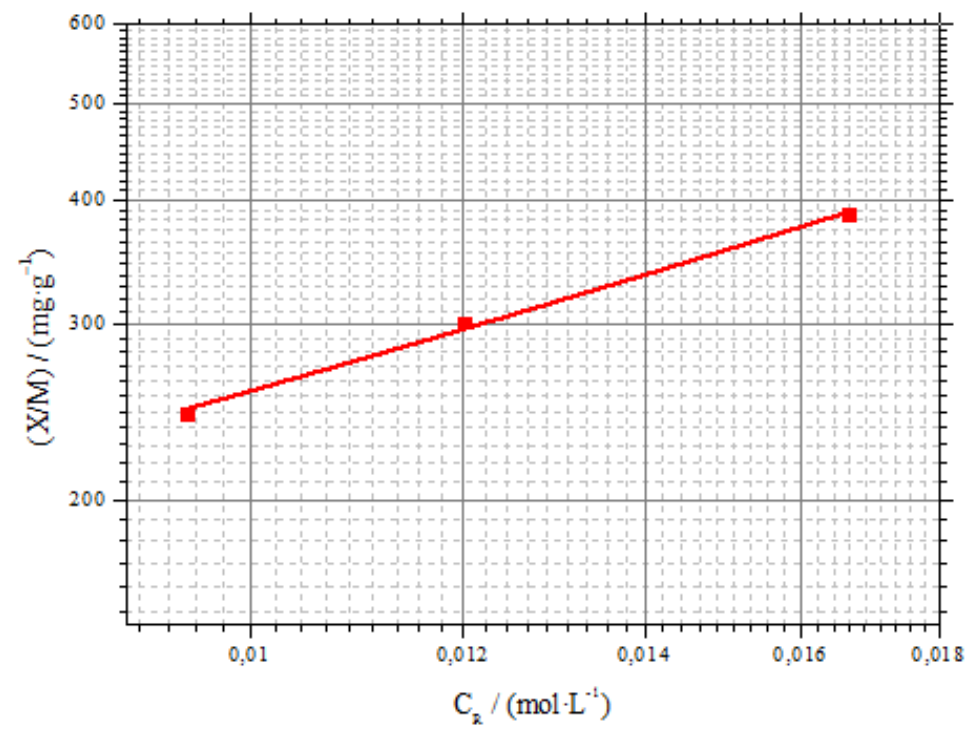

Figura 4. Isoterma de adsorção do iodo pelo PCL

$\mathrm{O}$ índice de iodo é igual ao valor de $\mathrm{X} / \mathrm{M}$ correspondente à concentração residual de $0,01 \mathrm{~mol} \cdot \mathrm{L}^{-1}$, resultando em $257,33 \mathrm{mg} \cdot \mathrm{g}^{-1}$. Adsorventes comerciais apresentam índices de iodo na faixa de 300 a $1200 \mathrm{mg} \cdot \mathrm{g}^{-1},{ }^{24}$ e de acordo com a NBR 2133, 1991b, carvões ativados para uso em estações de tratamento de água devem apresentar índice de iodo mínimo de $600 \mathrm{mg} \cdot \mathrm{g}^{-1} .^{18}$ Contudo, adsorventes não ativados de origem vegetal possuem índices de iodo inferiores aos de carvões ativados, conforme reportado na literatura de $9,84 \mathrm{mg} \cdot \mathrm{g}^{-1}$ para grãos de café desengordurados $^{25}$ e $198,12 \mathrm{mg} \cdot \mathrm{g}^{-1}$ para carvão ativado produzido a partir de sementes de goiaba. ${ }^{26}$

\section{Índice de Azul de Metileno}

Inicialmente, mediu-se o comprimento de onda de maior absorbância (pico de absorção) para diferentes concentrações de AM.

Com base nos resultados de absorbância, verificou-se que todas as soluções de AM apresentaram pico de absorbância máxima em $665 \mathrm{~nm}$. A partir destes dados, construiuse um gráfico da absorbância em função da concentração de AM que resultou na equação da regressão linear $\left(R^{2}=0,99971\right)$ de:

Abs $=(61,3 \pm 0,5) \cdot\left[\mathrm{C} /\left(\mathrm{g} \cdot \mathrm{L}^{-1}\right)\right]-(0,0134 \pm$ $0,002)$, em que Abs corresponde à absorbância, e C à concentração de AM residual. 
Os índices de AM para as três amostras resultaram em valores próximos a zero, indicando a não ocorrência da adsorção da molécula nos poros do PCL. De acordo com Di Bernardo e Dantas, 2005, a molécula de AM possui diâmetro médio de $0,8 \mathrm{~nm}$, mas é efetivamente adsorvida por poros de abertura superior a $1,3 \mathrm{~nm}$, preferencialmente de $2,0 \mathrm{~nm}^{27}$

Uma vez que o $\mathrm{PCL}$ possui poros com dimensão entre $10 \times 10^{3} \mathrm{~nm}$ e $15 \times 10^{3} \mathrm{~nm}$ em sua maioria, a adsorção seria possível. Assim, a adsorção pode ter sido impedida por repulsões entre a superfície do adsorvente e - AM, pois este se torna protonado em solução, e o PCL possui caráter ácido.
Contreras et al., 2012 obtiveram índice de azul de metileno de $178,7 \mathrm{mg} \cdot \mathrm{g}^{-1}$ para cascas de laranja secas utilizando soluções com concentrações variando de 50 a $500 \mathrm{mg} \cdot \mathrm{L}^{-1}{ }^{28}$; Khalfaoui et al., 2014 de 9,74 mg.g ${ }^{-1}$ para pó de cascas de laranja calcinadas, em solução de $100 \mathrm{mg} \cdot \mathrm{L}^{-1}{ }^{15}$

\section{Ponto de Carga Zero ( $\left.\mathrm{pH}_{\mathrm{PcZ}}\right)$}

Com base nos valores de $\mathrm{pH}$ inicial e final das soluções analisadas, construiu-se $\mathrm{O}$ gráfico da diferença de $\mathrm{pH}$ versus $\mathrm{pH}$ inicial (Figura 5), em que o valor do $\mathrm{pH}_{\mathrm{PCZ}}$ corresponde ao ponto onde a curva intercepta o eixo das abscissas, ou seja, 6,53.

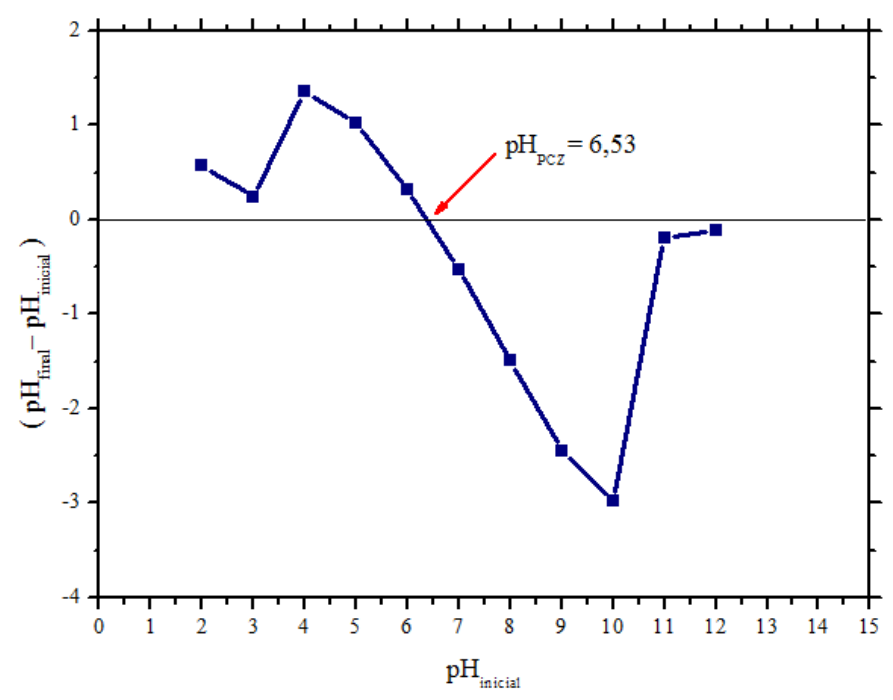

Figura 5. Representação gráfica do $\mathrm{pH}_{\mathrm{PCZ}}$

Em soluções com pH inferior a este valor, o PCL terá afinidade preferencialmente por ânions, enquanto soluções com $\mathrm{pH}$ superior a este valor deixarão a superfície do $\mathrm{PCL}$ com maior afinidade por cátions. Na literatura são encontrados valores de $\mathrm{pH}_{\mathrm{PCZ}} 3,5$ e 6,0 para cascas de laranja secas em estufa ${ }^{28,29}$ e 6,33 para carvão ativado produzido a partir de casca de laranja. ${ }^{30}$ Carvões ativados comerciais apresentam valores de $\mathrm{pH}_{\mathrm{PCZ}}$ em torno de 9,5. ${ }^{31}$ Observa-se decrescimento da curva em $\mathrm{pH}$ inicial 3,00 , possivelmente devido à baixa ionização dos grupos carboxílicos da celulose em pHs inferiores ao valor de $\mathrm{pK}_{\mathrm{a}}$ (variável de 3 a 5 para grupos carboxílicos). ${ }^{29} \mathrm{~A}$ diferença de 0,20 entre os valores inicial e final em $\mathrm{pH} 11,00$ sugere a desprotonação dos grupos ácidos da pectina. ${ }^{28}$ 
Curva de calibração para análise quantitativa do corante Direct Blue 86
A partir das diferentes concentrações, foram obtidos espectros de UV-visível, apresentado na Figura 6.

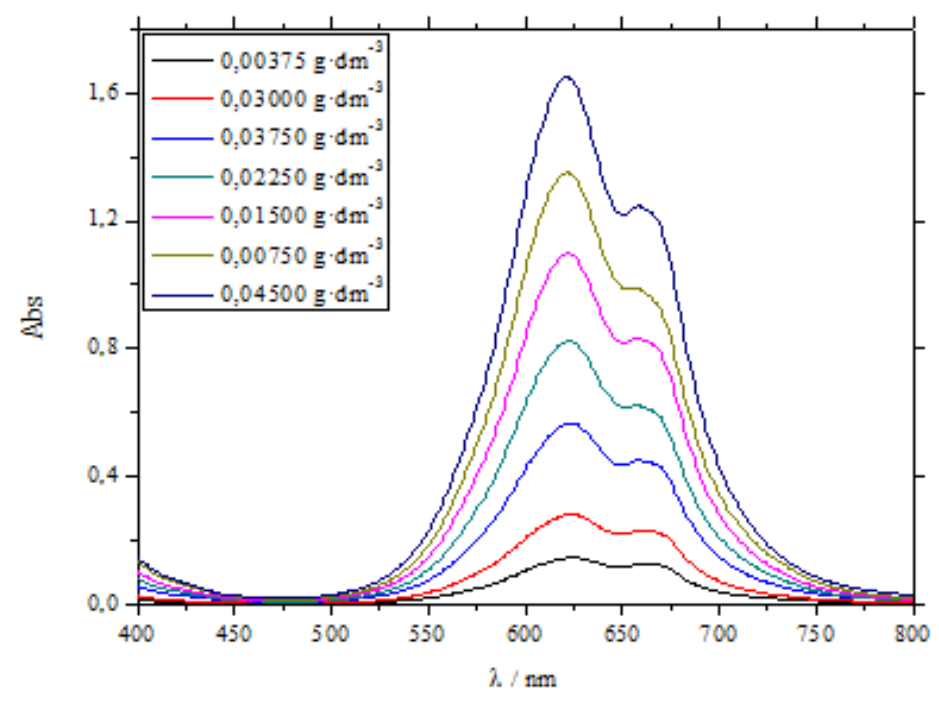

Figura 6. Espectros de UV-visível de soluções aquosas em diferentes concentrações do corante $D B$ 86, $\mathrm{pH} 6,51$

Através dos espectros de UV-visível foi possível obter o comprimento de onda com absorbância máxima de $620 \mathrm{~nm}$. Saien e Shahrezaei, 2007 obtiveram espectro de UVvisível similar à Figura 14, para o corante $D B$ $86 .{ }^{32}$
O gráfico da absorbância versus concentração da solução de corante filtrada e não filtrada, é apresentado na Figura 7.

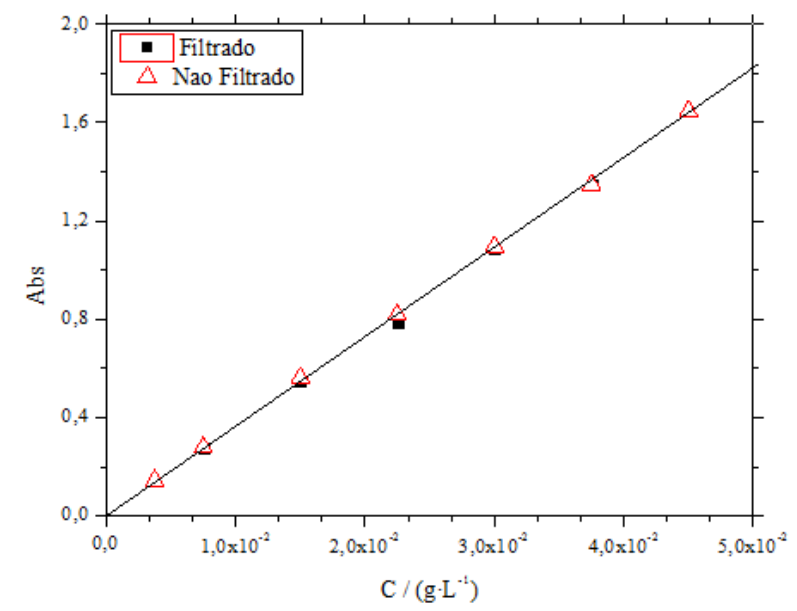

Figura 7. Absorbância em $620 \mathrm{~nm}$ versus concentração de soluções aquosas do corante $D B 86$ filtradas e não filtradas 
Não foi observada diferença significativa para as duas curvas. Mas, como nos ensaios de adsorção o adsorvente é separado da solução por filtração, foi considerada a curva de calibração com as soluções do $D B 86$ filtradas.

Análise quantitativa de corante adsorvido sobre pó de casca de laranja
A influência do tempo de contato no ensaio de adsorção é apresentada na Figura 8. Pode-se observar que com o passar do tempo a concentração não tende a um valor constante de concentração, que seria um indicativo de o sistema atingir equilíbrio.

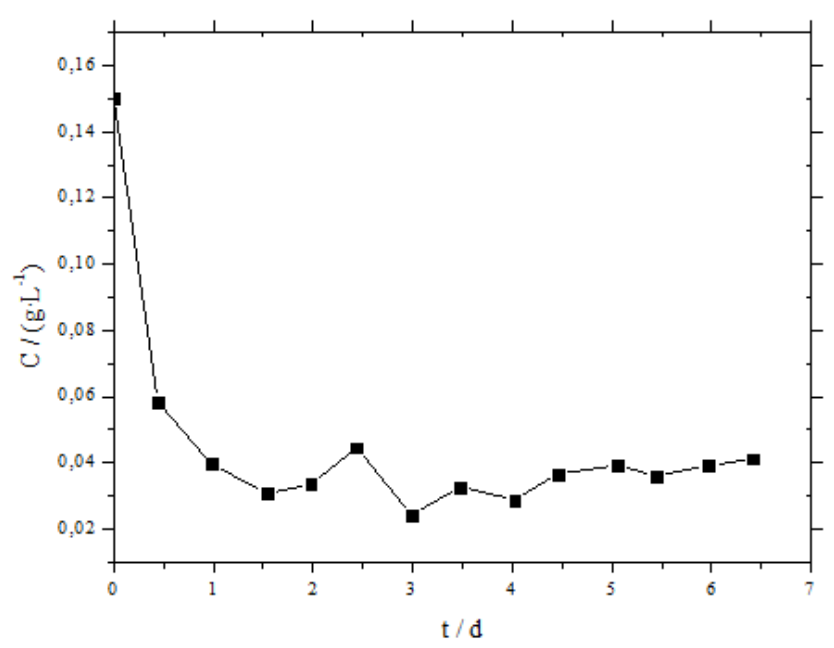

Figura 8. Concentração da solução aquosa do corante $D B 86$ versus tempo, após a adsorção a $30{ }^{\circ} \mathrm{C}$

Para investigar o não alcance do equilíbrio, foram obtidos espectros de UVvisível das soluções aquosas do corante $D B$ 86 após o ensaio de adsorção, apresentados na Figura 9.

É possível observar que o pico de absorbância máximo para o corante $D B 86$ foi alterado para $678 \mathrm{~nm}$ após o ensaio de adsorção comparando com o espectro UVvisível da solução de corante apresentado na Figura 6.
Com o intuito de verificar se havia alteração do pó da casca de laranja com o passar do tempo em contato com a solução aquosa de corante, as amostras do ensaio foram guardadas e lidas novamente após 46 d (Figura 10), e obtidos espectros de UVvisível para estas amostras (Figura 11).

Pelas Figuras 10 e 11, é possível observar alteração nos resultados após $46 \mathrm{~d}$, ao serem comparados com os resultados apresentados nas Figuras 8 e 9 . 


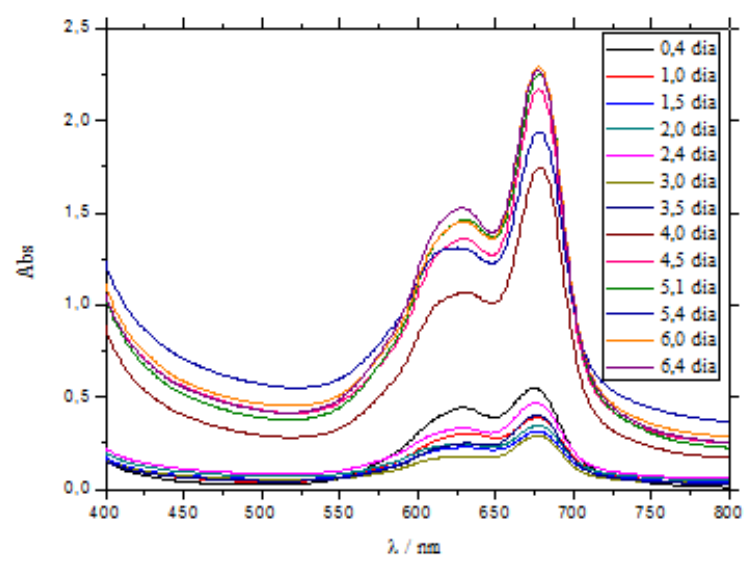

Figura 9. Espectros de UV-visível das soluções aquosas contendo o corante $D B 86$ após a adsorção a $30^{\circ} \mathrm{C}$

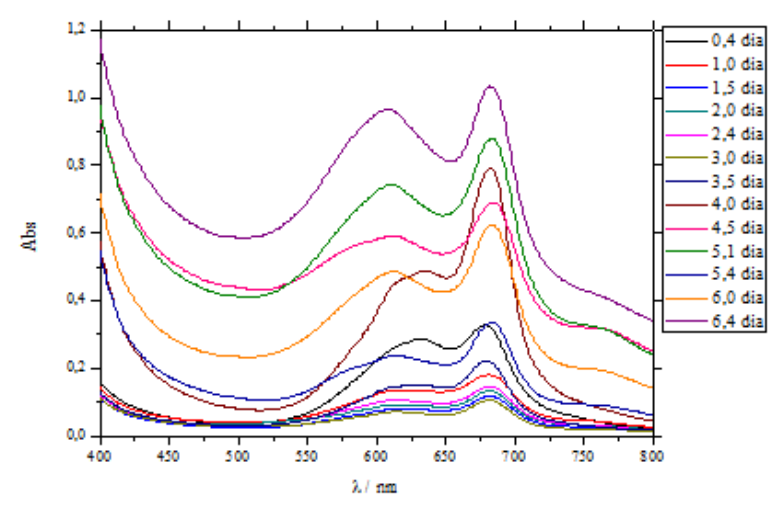

Figura 10. Espectros de UV-Visível após 46 d das soluções aquosas do corante $D B 86$ após a adsorção a $30^{\circ} \mathrm{C}$

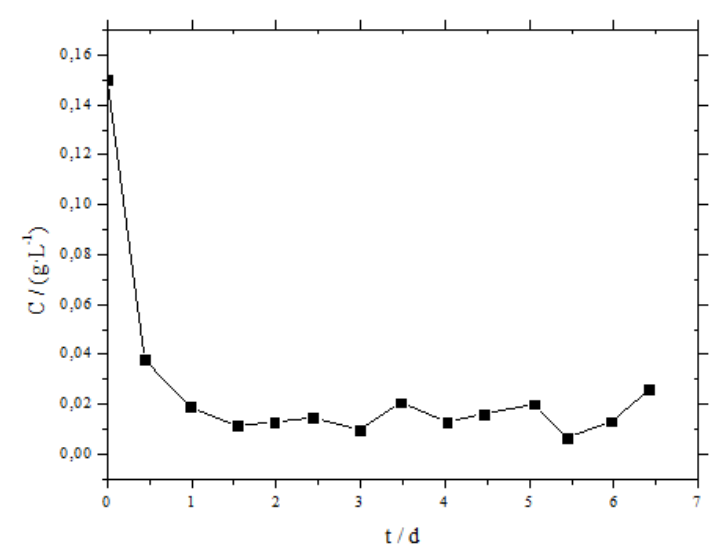

Figura 11. Releitura após 46 dias da concentração da solução aquosa do corante $D B 86$ versus tempo, após a adsorção a $30^{\circ} \mathrm{C}$

Também foi observada a presença de gás, indicando degradação das amostras devido à existência de micro-organismos, como verificado pela presença de fungos. Isto pode 
ser um dos motivos do sistema não ter atingido o equilíbrio nos ensaios de adsorção.

\section{Influência do pH na análise quantitativa do ensaio de adsorção}

Devido à alteração do $\mathrm{pH}$, de 6,51 para 5,03 após o tempo de $6 \mathrm{~d}$ e $12 \mathrm{~h}$ do ensaio, foram preparadas soluções com diferentes pHs para investigar sua influência na mudança do espectro de UV-visível (Figura 12). Foi possível observar que a mudança de $\mathrm{pH}$ acarretou na alteração nos espectros do corante, porém o pico de absorbância máximo continuou o mesmo, ou seja, a alteração do pico de máxima absorbância nos ensaios de adsorção com o $\mathrm{PCL}$ não é devido à mudança no $\mathrm{pH}$ do meio.

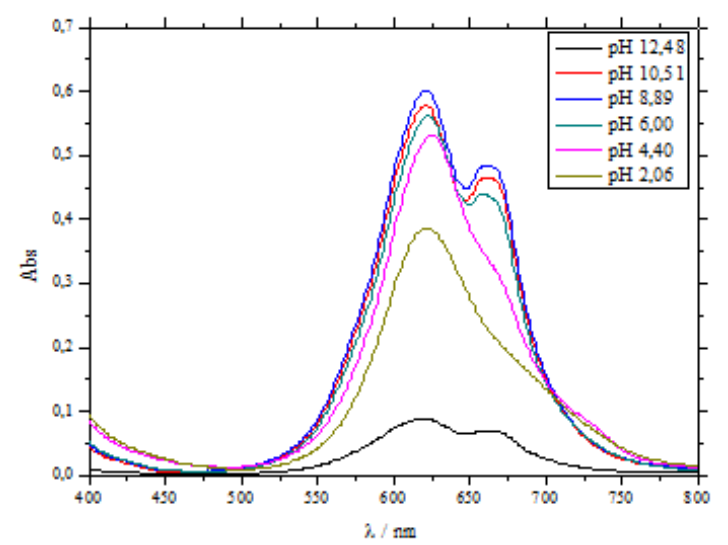

Figura 12. Espectros de UV-visível da solução de $D B 86 \mathrm{com} p H s$ ajustados em diferentes valores

Influência dos componentes da casca de laranja na análise quantitativa do ensaio de adsorção

Apenas na região do Ultravioleta do espectro de UV-visível do segundo ensaio, com água destilada e casca da laranja apareceram picos, que não são significativos para a investigação da alteração do espectro, devido ao pico de absorbância máxima para o corante $D B 86$ estar na região do Visível.

Como vários componentes estão presentes na casca de laranja, em destaque para Ácido Ascórbico (presente no flavedo e albedo), 0,3 \% de Beta- Caroteno, 42,5\% de Pectina, D-Limoneno (83-90\% do óleo total), $9,21 \%$ de Celulose, 16,9\% de açúcares solúveis (sendo a Sacarose em maior quantidade), ${ }^{33,34}$ é possível que algum destes componentes possa ter alterado o pico de absorbância máximo.
Com isso, foi colocada uma pequena quantidade de aproximadamente $0,1 \mathrm{~g}$ destes componentes em água destilada (componente + água destilada) e também na solução de corante (componente + solução do $D B$ 86), obtendo o espectro de UV-visível para posteriormente compará-los com $O$ espectro de UV-visível da solução do $D B 86$ (Figura 13).

Na Figura 13 foi possível notar que o DLimoneno é o responsável pela mudança na intensidade dos picos, pois reage com a solução de corante e o pico de maior intensidade foi alterado de $\lambda_{\text {máx }}=620 \mathrm{~nm}$ para $\lambda_{\text {máx }}=678 \mathrm{~nm}$.

Devido à alteração no espectro de UVvisível, não foi possível fazer a quantificação do corante após os ensaios de adsorção, impossibilitando a realização dos estudos de cinética e isoterma de adsorção. 


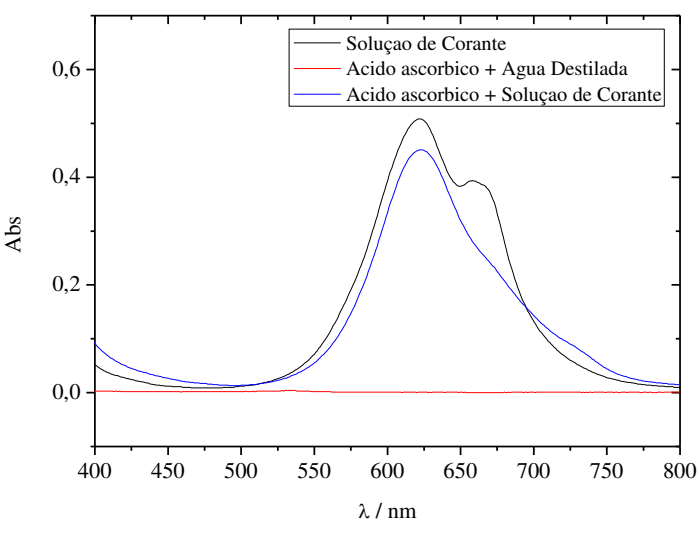

a)

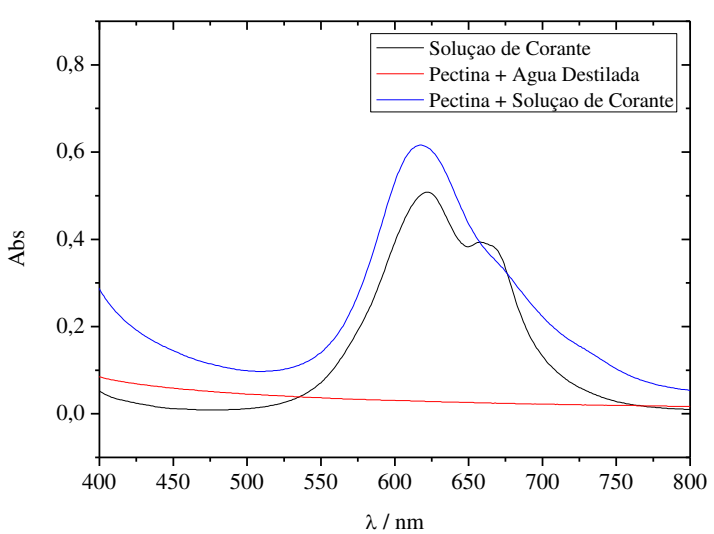

c)

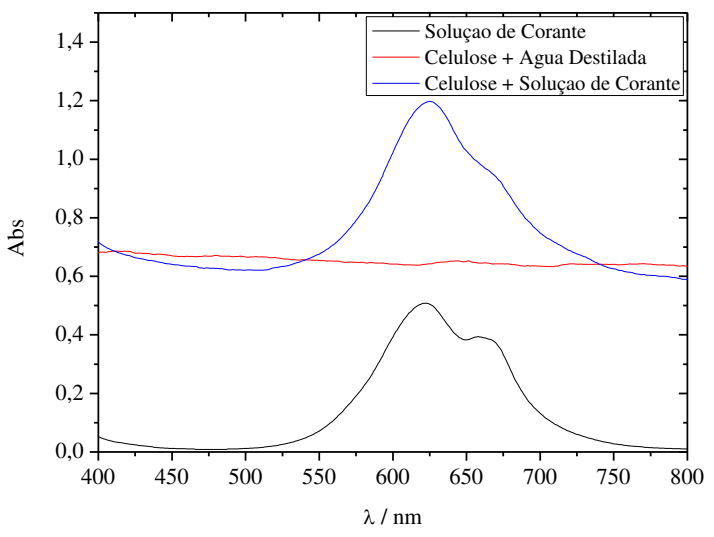

e)

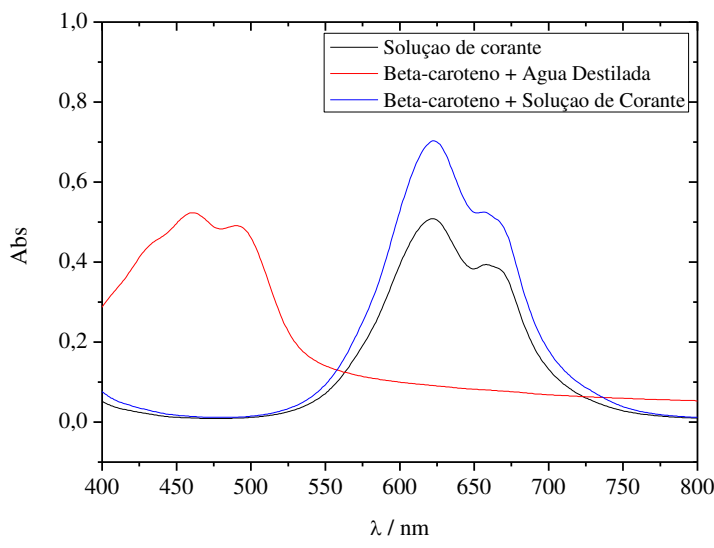

b)

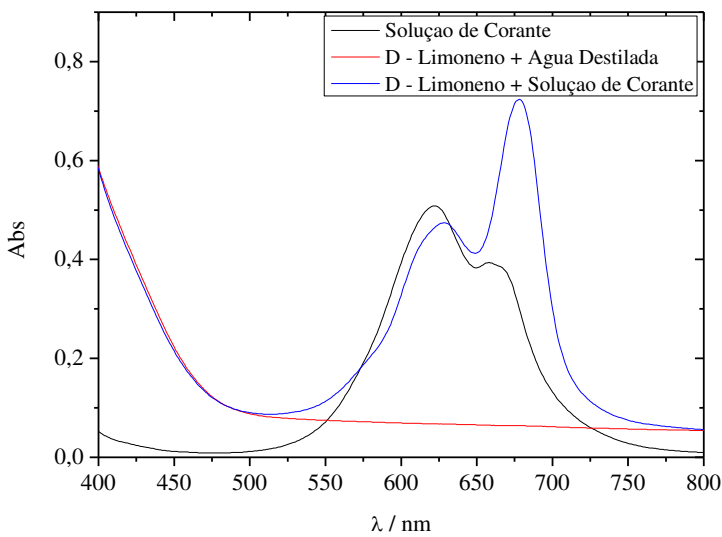

d)

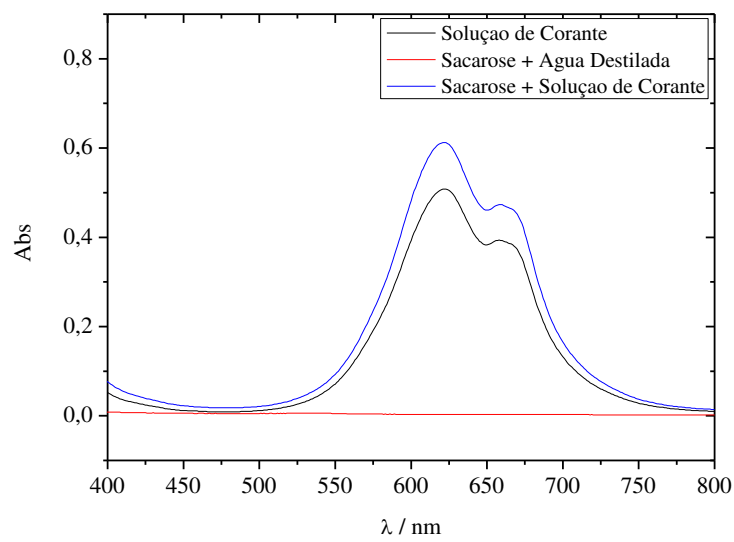

f)

Figura 13. Espectros de UV-visível. (a) Ácido Ascórbico; (b) Beta-Caroteno; (c) Pectina; (d) DLimoneno; (e) Celulose; (f) Sacarose

\section{Conclusões}

O PCL avaliado neste trabalho possui potencial como material adsorvente para o corante têxtil Direct Blue 86, uma vez que suas propriedades físico-químicas indicam estrutura porosa compatível com a adsorção de moléculas com dimensões de até $15 \mu \mathrm{m}$. O PCL apresentou teor de umidade abaixo de $8 \%$, atendendo a norma ABNT NBR 2133 e o 
teor de cinzas foi de $2,79(0,06) \%$, indicando poucas impurezas no material. $\mathrm{O} P C L$ preparado no laboratório apresentou propriedades semelhantes àquelas de materiais similares reportados na literatura, com exceção do índice de azul de metileno que não pôde ser calculado.

A metodologia empregada nos ensaios de adsorção não forneceu indicativo do sistema atingir equilíbrio, o que levou à investigação das possíveis causas.

A releitura das amostras após 46 dias da data do ensaio de adsorção indicou alteração nos picos com o passar do tempo e também foi verificada a existência de fungos e microorganismos, ou seja, pode ser que tenha ocorrido degradação das amostras.

Também foi possível identificar o DLimoneno como responsável pela alteração na intensidade dos picos. A presença deste componente inviabilizou a quantificação do corante após os ensaios de adsorção, através da variação do tempo de contato (cinética de adsorção), pH, temperatura e da isoterma de adsorção. Portanto, o método de adsorção, usando casca de laranja como adsorvente para o corante $D B 86$ como adsorvato não se mostrou eficiente nas condições deste estudo.

\section{Referências Bibliográficas}

${ }^{1}$ Garg, V. K. ; Gupta, R. ; Yadav, A. B.; Kumar, $R$. Dye removal from aqueous solution by adsorption on treated sawdust. Bioresource Technology 2003, 89, 121. [CrossRef] [PubMed]

${ }^{2}$ Cooper, P. Colour in Dyehouse Effluent. Society of Dyers and Colorists. Oxford: Alden Press, 1995.

${ }^{3}$ Ruthven, D. M. Principles of adsorption and adsorption process. Hardcover: John Wiley \& Sons, 1994.

${ }^{4}$ Pollard, S. J. T.; Fowler, G. D.; Sollars, C. J.; Perry, R. Low cost adsorbents for water and wastewater treatment - a review. The Science of the Total Environment 1992, 116, 3331. [CrossRef]
${ }^{5}$ El Nemr, A.; Abdelwahab, O.; El-Sikaily, A.; Khaled, A. Removal of Direct Blue-86 from aqueous solution by new activated carbon developed from orange peel. Journal of Hazardous Materials 2009, 100, 102. [CrossRef] [PubMed]

${ }^{6}$ Abdurrahman, F. B. ; Akter, M. ; ABEDIN, M. Z. Dyes Removal From Textile Wastewater Using Orange Peels. International Journal of Scientific \& Technology Research 2013, 2. [Link]

${ }^{7}$ ASTM - American Society of Testing And Materials. D2867/2004: Standard Test Method for Moisture in Activated Carbon. Estados Unidos, 2004.

${ }^{8}$ ASTM - American Society of Testing And Materials. D2866/1994: Standard Test Method for Total Ash Content of Activated Carbon. Estados Unidos, 1994.

${ }^{9}$ ABNT - Associação Brasileira De Normas Técnicas. NBR NM 248:2001: Agregados Determinação da composição granulométrica. Brasil, 2001.

${ }^{10}$ ABNT - Associação Brasileira De Normas Técnicas. NBR 12073:1991: Carvão ativado pulverizado - Determinação do número de iodo - Método de ensaio. Brasil, 1991(a).

${ }^{11}$ ASTM - American Society Of Testing And Materials. D4607/1994: Standard Test Method for Determination of lodine Number of Activated Carbon. Estados Unidos, 2014.

${ }^{12}$ Xavier, M. A. K. Trabalho de Conclusão de Curso (Tecnologia em Química Ambiental), Universidade Tecnológica Federal do Paraná, 2007.

${ }^{13}$ Couto Junior, O. M. Exame de Qualificação (Doutorado em Engenharia Química), Universidade Estadual de Maringá, 2012.

${ }^{14}$ Skoog, D. A.; Holler, F. J.; West, D. M. Fundamentos em Química Analítica. São Paulo: Editora Cengage Learning, 2014.

${ }^{15}$ Khalfaoui, A.; Bendjamaa, I.; Bensid, T.; Meniai, A. H.; Derbal, K. Effect of Calcination on Orange Peels Characteristics: Application of an Industrial Dye Adsorption. Chemical Engineering Transactions 2014, 38, 361. [CrossRef]

${ }^{16}$ Miranda, R.; Bustos-Martinez, D.; Blanco, C. S.; Villarreal, M. H. G.; Cantú, M. E. R. Pyrolysis of sweet orange (Citrus sinensis) dry 
peel. Journal of Analytical and Applied Pyrolysis 2009, 86, 245. [CrossRef]

${ }^{17}$ Kamsonlian, S.; Suresh, S.; Majumder, C. B.; Chand, S. Characterization of banana and orange peels: biosorption mechanism. International Journal of Science Technology \& Management 2011, 2. [Link]

${ }^{18}$ ABNT - Associação Brasileira De Normas Técnicas. NBR 2133: Carvão ativado pulverizado - Especificação. Brasil, 1991(b).

${ }^{19}$ Nassar, A. G; Abdel-Hamied, A. A.; ElNaggar, E. A. Effect of Citrus by-Products Flour Incorporation on Chemical, Rheological and Organolepic Characteristics of Biscuits. World Journal of Agricultural Sciences 2008, 4, 612. [Link]

${ }^{20}$ Mafra, M. R.; Igarashi-Mafra, L.; Zuim, D. R.; Vasques, E. C.; Ferreira, M. A. Adsorption of remazol brilliant blue on an Orange peel adsorbent. Brazilian Journal of Chemical Engineering 2013, 30, 6557. [CrossRef]

${ }^{21}$ Arami, M., Limaee, N. Y., Mahmoodi, N. M.; Tabrizi, N. S. Removal of dyes from colored textile wastewater by orange peel adsorbent: Equilibrium and kinetic studies. Journal of Colloid and Interface Science 2005, 288, 371. [CrossRef] [PubMed]

${ }^{22}$ IUPAC. International Union of Pure and Applied Chemistry. Compendium Of Chemical Terminology, 2a. ed., IUPAC, 1997.

${ }^{23}$ Xiao, H.; Gao, Z. The Application of Scanning Electron Microscope (SEM) to Study the Microstructure Changes in the Field of Agricultural Products Drying. In: KAZMIRUK, Viacheslav. Scanning Electron Microscopy 2012, cap. 11. [CrossRef]

${ }^{24}$ Malik, R.; Ramteke, D. S.; Wate, S. R. Physico-chemical and surface characterization of adsorbent prepared from groundnut shell by $\mathrm{ZnCl}_{2}$ activation and its ability to adsorb colour. Indian Journal of Chemical Technology 2006, 13, 319. [Link]

${ }^{25}$ Baek, M.; ljagbemi, C. O.; O, S.; Kim, D. Removal of Malachite Green from aqueous solution using degreased coffee bean. Journal of Hazardous Materials 2010, 176, 820. [CrossRef]
${ }^{26}$ Joseph, C. G.; Bono, A.; Krishnaiah, D.; Soon, K. O. Sorption Studies of Methylene Blue Dye in Aqueous Solution by Optimised Carbon Prepared from Guava Seeds (Psidium guajava L.). Materials Science (Medžiagotyra) 2007, 13, 1. [Link]

${ }^{27}$ Di Bernardo, L.; Dantas, A. D. B. Métodos e técnicas de tratamento de água. 2a. ed. São Carlos: RiMa, 2005.

${ }^{28}$ Contreras, E.; Sepúlveda, L.; Palma, C. Valorization of Agroindustrial Wastes as Biosorbent for the Removal of Textile Dyes from Aqueous Solutions. International Journal of Chemical Engineering 2012, 9, 9. [CrossRef]

${ }^{29}$ Khan, S.; Farooqi, A.; Danish, M. I.; Zeb, A. Biosorption of Copper (II) from aqueous solution using Citrus sinensis peel and wood sawdust: utilization in purification of drinking and waste water. International Journal of Research and Reviews in Applied Sciences 2013, 16, 297. [Link]

${ }^{30}$ Foo, K. Y.; Hameed, B. H. Preparation, characterization and evaluation of adsorptive properties of orange peel based activated carbon via microwave induced $\mathrm{K}_{2} \mathrm{CO}_{3}$ activation. Bioresource Technology 2012, 104, 679. [CrossRef] [PubMed]

${ }^{31}$ Regalbuto, J. R.; Robles, J.; The engineering of Pt/Carbon Catalyst Preparation. University of Illinois: Chicago, 2004. [Link]

${ }^{32}$ Saien, J.; Shahrezaei, F. Decolorization and mineralization of Direct Blue 86 by UV/TiO process: Investigations on the effect of operational parameters. Journal of Sciences (Islamic Azad University) 2007, 17, 64. [Link]

${ }^{33}$ Ladaniya, M. S. Citrus Fruit: Biology, Technology and Evaluation. Londres: Elsevier Inc., 2008.

${ }^{34}$ Rezzadori, K.; Benedetti, S. Proposições para Valorização de Resíduos do Processamento do Suco de Laranja. 2nd International Workshop / Advances in Cleaner Production, São Paulo, Brasil, 2009. [Link] 